\title{
TDAH nas redes sociais: caminhos para a medicalização da infância
}

\author{
TDAH en las redes sociales: caminos para la \\ medicalización de la infancia
}

\section{ADHD in social networks: ways to medicalization of childhood}

\author{
Fernanda Martinhago \\ ORCID ID: 0000-0002-2929-7739 \\ Universidade Federal de Santa Catarina, Brasil
}

Autor referente: martinhagofernanda@gmail.com

Historia Editorial

Recibido: 24/03/2018

Aceptado: 29/08/2018

\section{RESUMO}

A medicalização da infância é uma temática que está em evidência na contemporaneidade, devido a uma epidemia de transtornos mentais que atinge crianças e adolescentes. Nesta perspectiva, considera-se que uma parte do público infanto-juvenil está sendo prejudicada por diagnósticos psiquiátricos equivocados e tratamentos desnecessários. Portanto, a principal preocupação que rege esta pesquisa é com crianças e adolescentes que estão sendo rotulados com diagnósticos falsopositivos de transtornos mentais $\mathrm{e}$ "tratados" com intervenções medicamentosas como se tivessem patologias graves. O Transtorno de Déficit de Atenção e Hiperatividade (TDAH) foi elegido como tema principal deste estudo por apresentar elevada prevalência em diversos países. A partir deste contexto, foi estabelecido como objetivo desta pesquisa compreender como as redes sociais (comunidades virtuais do Facebook) são utilizadas para veicular estratégias biopolíticas, com intuito de articular 0 processo de medicalização da infância. A metodologia utilizada para 0 desenvolvimento da pesquisa foi a etnografia virtual em uma comunidade da rede social Facebook. Considera-se que as informações sobre o TDAH disseminadas nas redes sociais, identificadas como de caráter educativo, e somadas à publicidade, caracterizam uma vulnerabilidade do campo virtual que viabiliza a articulação da medicalização de infância. 
Palavras chave: Medicalização; Biopolítica; TDAH; Redes Sociais

\section{RESUMEN}

La medicalización de la infancia es una temática que está en evidencia en la contemporaneidad, debido a una epidemia de trastornos mentales que alcanza a niños y adolescentes. En esta perspectiva, se considera que una parte de la población infanto-juvenil está siendo perjudicada por diagnósticos psiquiátricos equivocados y tratamientos innecesarios. Por lo tanto, la principal preocupación que rige esta investigación refiere a niños y adolescentes que están siendo etiquetados con diagnósticos falsopositivos de trastornos mentales $y$ "tratados" con intervenciones farmacológicas como se tuviesen patologías graves. El Trastorno de Déficit de Atención e Hiperactividad (TDAH) fue elegido como tema principal de este estudio por presentar una elevada prevalencia en diversos países. A partir de este contexto, fue establecido como objetivo de esta investigación comprender cómo las redes sociales (comunidades virtuales de Facebook) son utilizadas para vehicular estrategias biopolíticas, con el propósito de articular el proceso de medicalización de la infancia. La metodología utilizada para el desarrollo de la investigación fue la etnografía virtual en una comunidad de la red social Facebook. Se considera que las informaciones sobre el TDAH diseminadas en las redes sociales, identificadas como de carácter educativo, y sumadas a la publicidad, caracterizan una vulnerabilidad del campo virtual que viabiliza la articulación de la medicalización de la infancia.

\section{Palabras clave: Medicalización; Biopolítica; TDAH; Redes Sociales}

\section{ABSTRACT}

Childhood medicalization is evident in the contemporaneous; due to an epidemic of mental disorders that affects children and adolescents. From this perspective, a part of the child and adolescent public is considered to be undermined by misdiagnosed psychiatric diagnoses and unnecessary treatment. Therefore, the main concern that governs this research is centered in children and adolescents that are being labeled with false positive diagnoses of mental disorders and "treated" with drug interventions as if they had serious pathologies. Attention Deficit Hyperactivity Disorder (ADHD) was chosen as the main theme of study because it has a high prevalence in several countries. From this context, we established as the objective of this research to understand how social networks (virtual communities of Facebook) are used to convey biopolitical strategies, with the purpose of articulating the process of medicalization of childhood. The methodology used for the development of the research was virtual ethnography in a community of the social network Facebook. We consider that the information about ADHD disseminated in social networks, identified as educational, and added to the publicity, characterize a vulnerability of the virtual field that facilitates the articulation of the medicalization of childhood.

Keywords: Medicalization; Biopolitics; ADHD; Social Networks 


\section{Introdução}

a contemporaneidade, diversos transtornos mentais são disseminados na
população por meio de uma rede formada pelos laboratórios farmacêuticos, os quais buscam a colaboração ativa dos médicos que fazem as prescrições dos medicamentos, bem como dos pacientes que as solicitam, dos pesquisadores que inventam os novos transtornos mentais, dos grupos de consumidores que defendem mais tratamentos e do papel fundamental da mídia e da internet para divulgar as informações. Frances (2015, p. 52) salienta que "a promoção da doença é a fina arte de vender problemas psiquiátricos como forma mais eficaz de empurrar os muitos lucrativos comprimidos psiquiátricos".

Os laboratórios farmacêuticos justificam que suas propagandas são também educativas, alegam que as pessoas aprendem sobre as doenças ao terem contato com anúncios diretos ao consumidor. O montante gasto em marketing é exorbitante, mas grande parte do orçamento é justificado como atividades educativas, mascarando que as despesas são para informação e não para promoção, assim, conseguem escapar da legislação imposta as atividades de marketing (Angell, 2007).

Acredita-se que grande parte das pessoas diagnosticadas com algum transtorno mental são vítimas do processo de medicalização. Foucault (1994) considera que a medicalização é um modo de integrar as condutas, os comportamentos e o corpo ao funcionamento da medicina, cuja intervenção ocorre de forma indefinida e ilimitada. Para Conrad (2007), a medicalização é descrita como um processo, em que é concebida como um problema pertinente à medicina e que necessita de uma intervenção médica. O termo "medicalizar" significa um fazer médico, sendo que a ênfase da análise desta temática está no excesso de medicalização e suas consequências. Portanto, a medicalização é considerada por estes autores (Foucault, 1994; Conrad e Schneider, 1992; Conrad, 2007) como a redução das questões sociais em problemas individuais a serem tratados pela medicina, tornando o sujeito o único 
responsável pelo seu comportamento dito desviante.

O processo de medicalização é articulado por estratégias biopolíticas, em que a vida e seus mecanismos passam a ser dominados por um saber poder que funciona como um agente de transformação, o qual possibilita o controle, por meio de cálculos e de intervenções no biológico, no corpo, exercendo assim, a gestão da população (Foucault, 2013). Dentre as estratégias biopolíticas utilizadas para exercer o biopoder, considera-se que o conceito de risco e as classificações do Manual Diagnóstico e Estatístico de Transtornos Mentais (DSM) são estratégias fundamentais para concretizar o processo de medicalização da infância.

No âmbito da saúde pública, a concepção de risco surge como um potencial para promover um evento nocivo e perigoso. Posteriormente, torna-se um campo do saber fundamentado por cálculos de probabilidades, os quais direcionam as práticas técnicopolíticas. Desse modo, o risco é considerado como um acontecimento previsível, por meio de estimativas das probabilidades, bem como do custo dos danos que poderia causar (Caponi, 2012; Mitjavila, 2002).

O DSM foi criado mediante a necessidade de organizar uma classificação diagnóstica, de modo que as patologias fossem estabelecidas em categorias padronizadas. Esse sistema visava estabelecer um consenso terminológico em relação às doenças, suprimindo assim as finalidades acadêmicas, a comunicação entre os clínicos, os aspectos legais, entre outras demandas (Dunker, 2014). A última edição desse Manual, DSM-5, publicada em 2013, gerou bastante polêmica, principalmente, com relação à sua consistência científica, e também por favorecer a prática médica e o mercado da indústria farmacêutica.

Assim, parte-se do pressuposto que o conceito de risco e as classificações do DSM veiculados nas mídias sociais, com a roupagem de conteúdos educativos para a saúde mental, são peças fundamentais para formar a engrenagem que constitui o processo de medicalização da infância. 
A medicalização possibilita um controle médico do social, ocorrendo uma despolitização da existência. Na medida em que o comportamento é medicalizado, o seu significado naquele momento e em um determinado contexto deixa de existir. Medicalizar é uma maneira de ignorar o que o comportamento está buscando falar. A implicação mais significativa do processo de medicalização está em transformar os problemas sociais em questões individuais, focalizando a fonte do problema no indivíduo e não no ambiente social, impossibilitando assim soluções coletivas ou sociais e outras intervenções que possam ser consideradas plausíveis (Conrad e Schneider, 1992; Conrad, 2007). Neste sentido, muitos problemas que não eram médicos passaram a ser considerados como tal, expandindo a jurisdição médica.

Diante deste contexto, desenvolve-se esta pesquisa em prol da saúde mental de crianças e adolescentes, os quais estão se tornando vítimas deste jogo de poder. $\mathrm{O}$ TDAH foi escolhido como tema principal desta investigação por se tratar de um transtorno com elevada prevalência em diversos países como Estados Unidos, Israel, Reino Unido e por ter como principal tratamento o uso do metilfenidato, comercializado como Ritalina (Whitaker, 2016). Tal transtorno é caraterizado pelos sintomas de hiperatividade, compulsividade e desatenção, que podem ser também considerados como comportamentos cotidianos. Essa vulnerabilidade do diagnóstico facilita que um número significativo de pessoas receba um diagnóstico falso-positivo, pois este transtorno atinge cerca de $5 \%$ a $10 \%$ da população infanto-juvenil (Frances, 2016; Whitaker, 2016, Breggin, 2001). Frances (2015) alerta-nos que os índices de TDAH triplicaram nos últimos anos. Ele salienta que o excesso de diagnósticos desse transtorno ocorre devido à pressão do marketing das indústrias farmacêuticas e aos benefícios que gera no âmbito escolar.

Nesse sentido, esta pesquisa teve como objetivo compreender como as redes sociais (comunidades virtuais do Facebook) são utilizadas para veicular estratégias biopolíticas, com intuito de articular o processo de medicalização da infância. 


\section{Ritalina e TDAH: "uma droga em busca de um transtorno"}

A Ritalina está sendo consumida por milhões de crianças para tratar o TDAH, sendo que o seu fabricante, Novartis, afirma que esta droga é a "solução" para este problema generalizado. Mas, por trás das relações públicas, está uma realidade devastadora, pois as crianças estão ingerindo uma droga, cujos efeitos negativos podem ser os mesmos da anfetamina e da cocaína que podem gerar distúrbios comportamentais, supressão de crescimento, tiques neurológicos, agitação, dependência e psicose (Breggin, 2001).

Whitaker (2011) salienta que, há cerca de 20 anos, nos Estados Unidos, começou a se prescrever regularmente medicamentos psiquiátricos para crianças e adolescentes, 0 que resultou, atualmente, em que um a cada 15 estadunidenses sofram com alguma patologia mental grave, condenando assim, milhares de pessoas a patologias crônicas. Esse quadro mostra que este modelo de atenção à saúde faz mais mal do que bem.

Breggin (2001) afirma que cada vez mais crianças americanas estão consumindo drogas para que haja um controle de suas mentes e comportamentos. O autor ressalta que nunca na história de qualquer sociedade ou nação houve uma experiência em massa do uso de drogas em crianças, bem como nunca tantos pais receberam a informação de que seus filhos necessitam de medicamentos psiquiátricos para resolver as dificuldades na escola e no lar. É uma situação sem precedentes que talvez explique o porquê do aumento de transtornos mentais.

No início da fabrição da Ritalina, o laboratório farmacêutico tinha como objetivo atingir outro público, de modo bastante distinto da atualidade. A Ritalina foi aprovada pela primeira vez para uso em adultos durante a metade da década de 1950, para tratar pacientes deprimidos e geriátricos, em quem o comportamento era muito diferente do de crianças hiperativas. O Laboratório Farmacêutico Ciba, atualmente denominado de Novartis, criou o medicamento que, na época, foi comercializado como "pep pill", uma 
pílula mais forte que a cafeína, todavia não tão poderosa quanto outros estimulantes, como a Benzedrina. Os anúncios mostravam pessoas intensamente deprimidas, que viveram em hospitais psiquiátricos, bem como fotos comparativas do antes e depois de pacientes idosos ou donas-de-casa. Apesar dos esforços da Ciba para comercializar a Ritalina, o medicamento não teve êxito. Entretanto, psiquiatras que trabalhavam em uma instituição psiquiátrica infantil, nos Estados Unidos, já haviam percebido, desde a década de 1930, que o estimulante poderia ter um efeito positivo no desempenho acadêmico e no comportamento das crianças problemáticas (Smith, 2012).

Conrad e Schneider (1992) lembram-nos que, em 1937, Charles Bradley havia descoberto que as anfetaminas tinham um ótimo efeito na alteração de comportamentos ou problemas de aprendizagem. Dentre as 30 crianças que ele tratava, $50 \%$ apresentavam mais moderação no comportamento. Posteriormente, ao interromperem a medicação, retornaram a apresentar o mesmo comportamento anterior ao uso do medicamento.

Mas, somente em meados da década de 1950, o metilfenitado (Ritalina) vêm à tona como uma nova descoberta, um estimulante com muitas qualidades de anfetaminas sem alguns dos indesejáveis efeitos colaterais (Conrad e Schneider, 1992). Assim, devido à preocupação com as habilidades educacionais das crianças americanas durante a Guerra Fria, a Ciba investiu em um novo público para o consumo da droga, crianças em idade escolar (Smith, 2012).

Em 1961, a Food and Drug Administration (FDA) americana aprovou a comercialização da Ritalina para crianças, tornando-se um sucesso de vendas. A descoberta de outros medicamentos psiquiátricos para crianças, na mesma época, talvez tenha contribuído para a Ritalina tornar-se um tratamento aceitável. A princípio, a Ritalina era "uma droga em busca de um transtorno" e, posteriormente, parece que se tornou a droga "certa" para os tempos (Smith, 2012). 
Desde o início da década de 1960, houve um número significativo de publicações demonstrando preocupação com este tratamento medicamentoso da desordem do comportamento. Neste mesmo período, ocorreu um aumento significativo de publicidade da patologia nos meios de comunicação. Assim, a hipercinesia tornou-se o problema psiquiátrico mais comum na infância, o que propiciou o estabelecimento de clínicas especiais para o tratamento e uma quantidade significativa de verbas federais foi destinada para investigações etiológicas da doença e o desenvolvimento de pesquisas sobre o tratamento. Além disso, fora da profissão médica, os professores desenvolveram um conhecimento clínico dos sintomas da hipercinesia e o seu tratamento (Conrad e Schneider, 1992).

Antes dos anos 1960, praticamente não havia ações promocionais ou propagandas para o uso destes medicamentos com relação a desordens da infância. A partir da aprovação da Ritalina para crianças, algumas das maiores indústrias farmacêuticas iniciaram um processo de divulgação, direcionado e limitado principalmente ao setor médico. Porém, algumas das publicidades foram direcionadas ao setor de educação. Esta publicidade foi provavelmente significativa para dar visibilidade à nova desordem descoberta, trazendo informações sobre seu diagnóstico e tratamento.

Uma das principais tendências que motivaram o crescimento do diagnóstico e tratamento de hipercinesia, considerada a grande revolução farmacêutica em saúde mental, foi o uso de medicamentos psicoativos em pessoas com doenças mentais desde 1955, gerando confiança na indústria farmacêutica sobre a abordagem de problemas mentais e comportamentais. Nas décadas de 1960 e 1970, cresceu o interesse por saúde mental infantil, sob o argumento de que estas desordens em crianças vinham sendo ignoradas nos últimos anos.

No decorrer da década de 1970, o uso da Ritalina foi crescendo gradativamente, alcançando em torno de 150.000 crianças nos Estados Unidos. Posteriormente, a publicação do DSM-III, em 1980, identificou pela primeira vez o Transtorno de Déficit 
de Atenção (TDA) como uma patologia, cujos sintomas principais já eram hiperatividade, desatenção e impulsividade. Na edição revisada do DSM-III, em 1987, a psiquiatria ampliou as fronteiras diagnósticas do transtorno, redenominando para Transtorno de Déficit de Atenção com Hiperatividade. Nesta época, a Ciba-Geigy ajudou a fundar um grupo de apoio a pacientes com TDAH, denominado Crianças e Adultos com Déficit de Atenção e Hiperatividade (CHADD - sigla em inglês). Este, por sua vez, começou a conscientizar a população sobre a patologia e pressionou o Congresso para que o TDAH se configurasse como uma discapacidade e fosse incluído na Lei de Indivíduos com Discapacidade para a Educação. Em 1990, havia quase um milhão de crianças diagnosticadas, número que foi duplicando no decorrer dos anos seguintes. Estima-se em torno de 3,5 milhões o número de crianças nos Estados Unidos que tomam um estimulante em função do TDAH (Whitaker, 2011). Breggin (2001) nos revela que, nos Estados Unidos, a ação coletiva Ritalin foi estabelecida contra a Novartis, CHADD e a American Psychiatric Association (APA), a qual alega "fraude" e "conspiração" tanto para a promoção excessiva do diagnóstico de TDAH, quanto para o seu tratamento com a medicação Ritalina. A Novartis é acusada de promover o diagnóstico e a venda de Ritalina por meio de literatura promocional e formação de representantes de vendas que não informaram aos consumidores (médicos, escolas, etc) sobre os perigos do metilfenidato. Este Laboratório, bem como a CHADD, também são cobrados por promover e apoiar (com uma suposta neutralidade) a implementação cada vez maior de diagnósticos de TDAH, aumentando significativamente as vendas de Ritalina. A APA sofre a acusação de conspiração por colaborar e cooperar ao receber contribuições financeiras da Novartis, entre outras indústrias farmacêuticas.

Os grupos de apoio relacionados ao TDAH, tanto virtuais quanto presenciais, são comuns nos Estados Unidos. Compostos por diferentes pessoas interessadas no tema, o seu alcance vai desde comunidades pontuais até associações internacionais 
(Conrad e Bergey, 2014). No Brasil, não temos a mesma tradição, entretanto, existem associações de familiares e pacientes com TDAH, autismo, entre outras patologias mentais, que desempenham um papel de divulgar informações e propiciar melhores condições de tratamento e cidadania (Bianchi et al, 2016).

O grupo mais conhecido no Brasil é a Associação Brasileira de Déficit da Atenção (ABDA), uma entidade sem fins lucrativos, fundada em 1999, que tem como principal objetivo divulgar o conhecimento sobre o TDAH. Várias revistas e publicações científicas citam o site da ABDA (www.tdah.org.br), que tem em torno de 200 mil acessos por mês (Bianchi et al, 2016; Collares e Moysés, 2014).

Angell (2007) alerta que o marketing disfarçado para a venda de medicamentos ocorre também nos grupos de apoio aos pacientes:

Muitos destes grupos não passam de fachadas para os laboratórios farmacêuticos. Pessoas sofrem de uma determinada doença acreditam que encontraram uma rede de apoio dedicada a aumentar a conscientização do público com relação à doença, mas, na realidade, essa rede é um meio para os laboratórios farmacêuticos promoverem seus medicamentos. Algumas pessoas nem sabem que há um laboratório por trás do seu grupo de defesa, outros acreditam que os laboratórios só querem ajudar as pessoas (p.167).

As associações para pessoas com transtornos mentais se apresentam com caráter de apoio, entretanto, são financiadas pelos laboratórios farmacêuticos, o que configura conflito de interesses. Assim, compactuam com a disseminação de estratégias biopolíticas, atingindo um grande público pela sua atuação no campo virtual, incitando a formação de comunidades e disseminando as informações fornecidas pelos seus apoiadores e financiadores.

\section{Metodologia}

O método de pesquisa utilizado para o investigar a comunidade virtual da rede social 
Facebook foi a etnografia virtual. As redes sociais e suas respectivas comunidades virtuais são lugares onde instituições e pessoas se encontram para divulgar e discutir informações, trocar ideias, compartilhar suas angústias e conquistas, enfim, um ambiente vasto em informações disponíveis publicamente.

A comunidade virtual da ABDA foi alvo da pesquisa por ser justamente proveniente do site da ABDA, citado por pesquisadores como de forte influência no público, que recebe apoio e/ou patrocínio de associações profissionais, federações e empresas nacionais e internacionais, dos laboratórios farmacêuticos Novartis e Shire, entre outras instituições (Bianchi et al, 2016; Collares e Moysés, 2014). A entidade é composta não somente por familiares e pessoas diagnosticadas, mas também por médicos e pesquisadores internacionais que atuam fortemente no grupo. Esta Associação é um importante meio de difusão de informações para profissionais e leigos, com a predominância do discurso biomédico sobre o TDAH, bem como através de revistas que legitimam este transtorno como orgânico. Neste site, são divulgadas as causas, diagnóstico e tratamento do TDAH, conselhos para familiares e pacientes, atividades e considerações dos profissionais que atuam no campo, capacitação para profissionais da saúde e educação sobre o TDAH.

Apesar de as postagens dos participantes esterem publicadas em um ambiente virtual público, buscou-se preservar o anonimato dos sujeitos da pesquisa, cuja identificação foi realizada apenas com as letras iniciais referentes aos nomes que eles se identificavam nas redes sociais.

Para realizar a seleção dos dados constatou-se que na comunidade virtual da ABDA, as imagens sobre o TDAH e os comentários sobre estas predominavam no site. Observou-se que não havia frequência de diálogos nesta comunidade, mas algumas intervenções realizadas pelo mediador identificado como da ABDA. Foram então selecionadas as imagens, cujos conteúdos eram sobre o TDAH, em que os comentários apresentavam de algum modo uma identificação com as imagens. O foco 
principal da pesquisa está nos comentários que as pessoas fazem com relação à imagem postada na comunidade virtual. O período de investigação no campo virtual foi de maio de 2015 a setembro de 2016 .

A análise dos conteúdos angariados na pesquisa foi embasada na teorização foucaultiana, uma vez que as teorias propostas por Foucault e "suas correlatas metodologias são mais ferramentas do que máquinas acabadas" (Veiga-Neto, 2009, p. 91). Foucault não considerava que o método é um caminho seguro, em função de que nada é previsível, nada é seguro, nem o ponto de saída, nem o percurso, nem o ponto de chegada. O caminho é construído no próprio ato de caminhar, portanto, não há um solo externo por onde se possa caminhar (Veiga-Neto, 2009), mas um percurso que vai se delineando na trajetória da pesquisa.

\section{Resultados e discussão}

\section{Comunidade Virtual da ABDA}

A ABDA é uma entidade que tem como missão: divulgar informações científicas sobre - TDAH, capacitar profissionais de saúde e educação, oferecer suporte através de grupos de apoio e orientações às pessoas diagnoticadas e seus familiares. Esta Associação defende princípios norteadores que foram instituídos com base na Carta de Princípios sobre TDAH da National Consumer's League (Liga de Defesa do Consumidor) dos Estados Unidos. A visão, enquanto organização, é ser a referência na divulgação do TDAH na América Latina. Enquanto entidade que pretende ser referência na divulgação do TDAH, esta utiliza as mídias e redes sociais para alcançar este objetivo, pois são excelentes meios para se propagar informações. O campo virtual é bastante amplo, podendo disseminar informações por diversos países ao mesmo tempo. Deste modo, ter uma comunidade virtual é extremamente importante para atingir este objetivo. Apresenta-se a seguir alguns dos conteúdos postados na comunidade virtual da ABDA e os seus respectivos comentários. 


\section{A relação escola - professor - família}

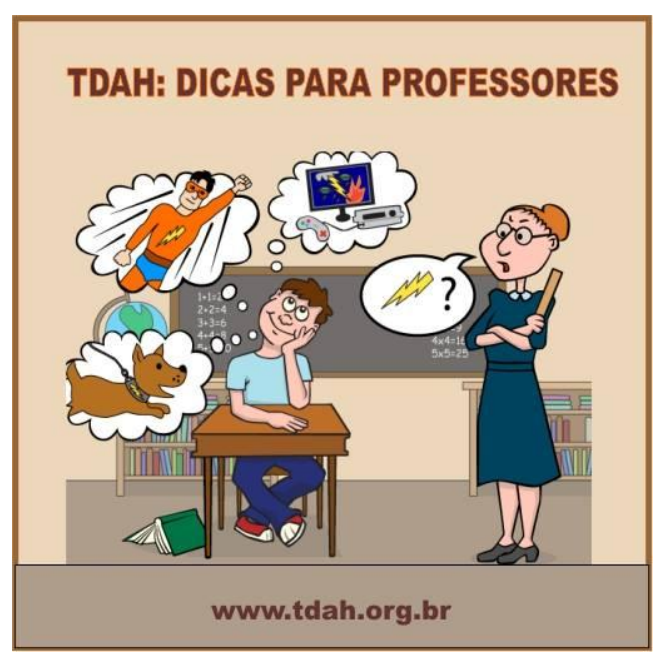

Figura 1. Professores ABDA sobre TDAH

Fonte: Facebook ABDA, 2016

As dicas para professores, que aparecem na figura 1, se referem a um texto escrito pela ABDA com estratégias para serem utilizadas em sala de aula, com intuito de diminuir os prejuízos decorrentes dos comportamentos referentes ao TDAH. Por exemplo: estabeleça rotinas, crie regras da sala de aula, sentar na frente na sala de aula, etc.

A figura 1 apresenta uma professora com uma régua na mão, objeto que representou um instrumento de punição no âmbito escolar por um longo período, com uma expressão e postura de poder em relação a um aluno que não presta atenção. As famosas palmatórias eram o método de disciplina escolar para os alunos considerados indisciplinados, para os quais hoje se dá o diagnóstico de TDAH.

O cenário da figura talvez transpareça mais com um quadro que se refere à infância de décadas passadas, o que estaria mais relacionado aos pais das crianças e às possíveis dificuldades e angústias que estes passaram durante a sua infância. Ao se identificarem com o quadro, os pais talvez estejam projetando a cena em seus filhos. O fato de ver os filhos passarem pelas mesmas angústias escolares que passaram em 
sua infância, possivelmente facilite para acreditar que, nos tempos contemporâneos, com o "avanço" da ciência, haja uma medicação para resolver esta questão. Por que deixariam os filhos sofrerem se já existe um remédio para isto? O que provavelmente muitos pais não se dão conta é que medicam seus filhos por um sofrimento que é deles, que revivem isto com os filhos. O comentário de FV revela seu sofrimeno: "Eu sofri minha infância inteira e sofro ainda um pouco hoje por causa disso. Na infância eu era taxado de "lesado", muitas ofensas partiam de professores que não tem conhecimento sobre isso [..]", ele relata o quanto sofreu na infância e como era discriminado pelos próprios professores.

A psiquiatria está resgatando uma infância, a qual ela mesma construiu como problemática, a partir do momento em que busca por meio desta constituir as patologias mentais, transmitindo a ideia de que é na infância que os traumas se constituem. "Corrigir, educar, controlar, medicalizar a criança é evitar o descaminho do adulto virtual que nela há" (Carvalho, 2015, p.25). Conforme Foucault, qualquer desvio normativo do adulto é buscado na sua infância a origem destes desvios, portanto, ela é o foco das estratégias de governo.

A escola tem como função ensinar a obedecer às regras e imbuir conhecimentos determinados por padrões curriculares, ou seja, é um espaço disciplinador. Há pouco tempo atrás, os castigos físicos faziam parte do modo como se obtinha uma boa formação. Segundo Augusto (2015, p.13), "a palmatória, a humilhação diante dos colegas, as separações e as demarcações claras entre bons e maus alunos no interior das salas de aula compunha os castigos de toda sorte". O autor acrescenta que estes castigos ainda estão presentes no imaginário dos adultos escolarizados e de alguns professores simpatizantes a estas práticas, pois, no passado, esta rigidez pedagógica representava o progresso e o acesso à educação universal.

Nos comentários, pode-se observar que CC desacredita na atuação dos professores, por alguns deles não reconhecerem o TDAH, conforme relata: "Uma pena em que 
existam professores que entendem que o aluno faz 'corpo mole' [...]. Pois o TDAH persiste e a má vontade de alguns professores também". O participante AA reforça que as crianças com TDAH são capazes e inteligentes, mas precisam de tratamento: "Concordo que necessitam de ajuda sim, mas não que sejam tratados como não capacitados porque todos são inteligentes e capazes, só necessitam de ajuda na concentração que é o ponto crucial do TDAH". Todos os comentários relativos à figura 1 remetem à importância do reconhecimento do TDAH e seu tratamento. O contexto educacional torna-se um espaço para o desenvolvimento de tecnologias normatizadoras, disciplinares, cuja função é enquadrar as crianças em classificações. Aquelas que escapam às normas estão sujeitas a receber um rótulo psiquiátrico e, uma vez que se identificarem com o diagnóstico, jamais deixarão de ser consideradas como anormais, pois passarão a agir de acordo com o transtorno e as pessoas que fazem parte do seu contexto passarão a tratá-las sempre considerando a sua situação patológica (Hacking, 2000).

\section{Transformando o normal em patológico}

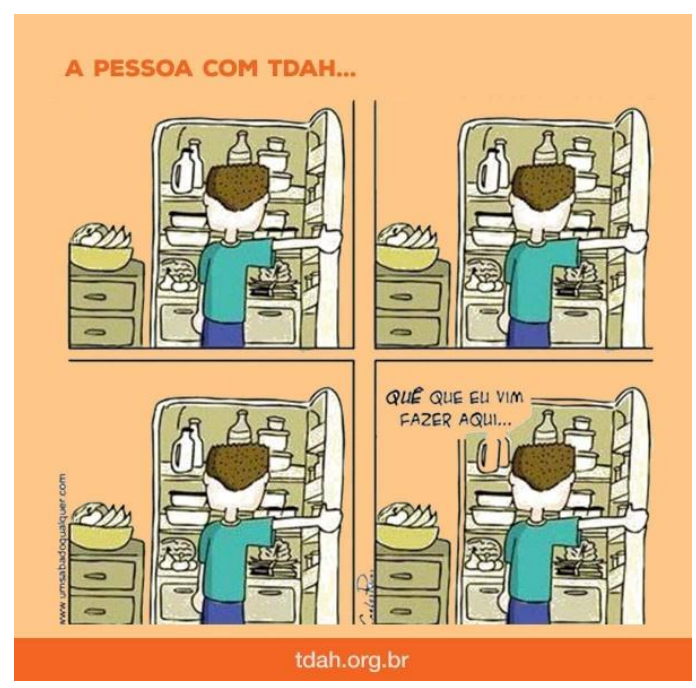

Figura 2. Cotidiano - ABDA sobre TDAH

Fonte: Facebook ABDA, 2016

A figura 2 representa uma cena comum do cotidiano de qualquer pessoa, em que vamos buscar algo e logo não lembramos o que vamos buscar. Entretanto, está 
mencionado na parte de cima "a pessoa com TDAH..." indicando que é uma cena de uma pessoa com o transtorno. Desta maneira, algumas pessoas que acessam esta comunidade e mediante a credibilidade por ser uma Associação que orienta as pessoas sobre o TDAH, passam a acreditar que este sintoma é um indício da patologia.

Apesar de a figura ser questionada por VZ em seu comentário: "Isso acontece com todo mundo, não vale usar isso como único pra dizer que é TDAH", a intervenção da pessoa que monitora as mensagens na comunidade virtual da ABDA induz a uma anormalidade pelo processo de repetição do comportamento, o que justifica como um indicativo de transtorno mental: "Nós que temos TDAH, bem sabemos o quanto é irritante e desgastante, passar o dia TODO, o tempo TODO, refazendo coisas, indo e voltando várias vezes aos lugares para fazer o que esquecemos." (VZ).

Conforme relata Frances (2016), não se deve converter em pacientes pessoas que são saudáveis e ignorar aquelas que estão realmente doentes. A intervenção deveria ser justamente o contrário; alertar que as pessoas que não necessitam de tratamento que o evitem, e para aqueles que realmente estão enfermos que o procurem. Muitas pessoas são prejudicadas por excesso de tratamento médico e outras são negligenciadas. A questão é: em que parâmetros os profissionais estão se baseando para definir o que é patológico ou não?

Carvalho (2015) diz que ser considerado "normal" significa que pode ser incapaz para determinadas tarefas, bem como o sujeito considerado "anormal" é capaz de fazer aquilo que o dito "normal" não poderá fazer. Esta postura significa "politizar a vida em sua condição humana" (p.31), considerando as diferenças de cada sujeito.

Assim, é imprescindível que se desenvolva o senso crítico em relação às teorias que suscitam diagnósticos falsos-positivos, as quais apresentam embasamento científico duvidoso, como o DSM (Dunker, 2014; Caponi, 2014; Frances, 2016). Frances (2016) defende que a medicina e a psiquiatria precisam de controle, de reformulação e 
redirecionamento.

\section{O risco de não tratar o TDAH}

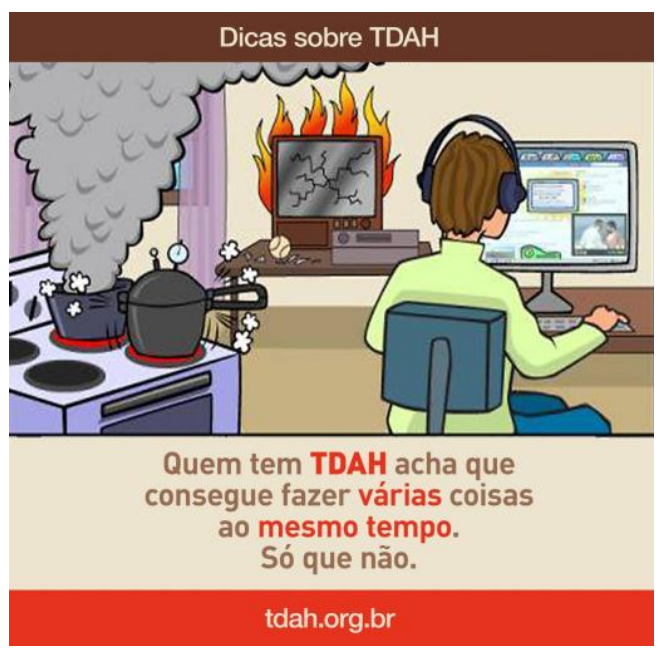

Figura 3. Atividades diversas - ABDA sobre TDAH

Fonte: Facebook ABDA, 2016

A figura 3 representa o risco de não tratar o TDAH, "acha que consegue", ou seja, vai tentar fazer e nada vai dar certo. Nos comentários, as pessoas identificam-se com suas próprias tarefas do dia a dia e alguns episódios recorrentes em seu cotidiano. Nada que possa caracterizar uma patologia. Como no relato de NG: "Começar várias coisas e não conseguir concluir nenhuma, deixar os amigos no vácuo porque lembrou que deixou a panela no fogo, desligar a panela e lembrar que esqueceu de estender a roupa..."

Aparece na figura 3 também o risco de colocar fogo na casa, de estragar equipamentos, inclusive riscos que poderiam levar a uma fatalidade, como um acidente grave. Neste caso, pode-se refletir com base na concepção de biopolítica em que os "dispositivos de segurança são pautados por uma economia do risco e da intervenção, onde não se trata mais de adestrar ou disciplinar" como na era dos dispositivos disciplinares (Silveira, 2015, p. 59). Foucault (2008) explica que os dispositivos de segurança atuam maximizando aspectos positivos de modo que 
tenham visibilidade e minimizam aspectos como o risco e o inconveniente, mesmo cientes de que estes nunca serão suprimidos. O risco se constitui como a probabilidade de o sujeito sofrer algum dano, de maneira que o outro lado, aquele pertinente à probabilidade, ou seja, o de não sofrer um dano, permanece obscuro.

\section{Propaganda do TDAH}

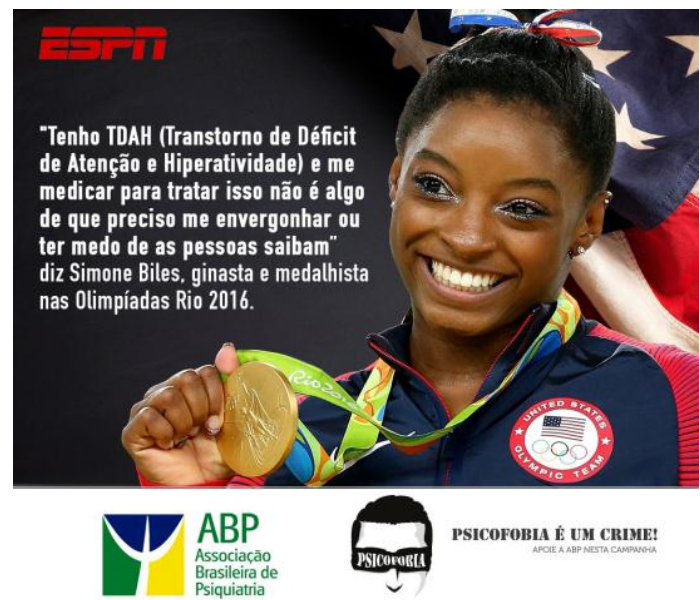

Figura 4. Atleta olímpica - postagem da ABDA sobre o TDAH

Fonte: Facebook ABDA, 2016

A figura 4, apesar de não ter sido elaborada pela ABDA, foi compartilhada em sua comunidade virtual. Simone Biles, estadunidense, com 19 anos, é destaque nas Olimpíadas Rio 2016, conquistando 5 medalhas e entrando para o grupo de maiores medalhistas na história da ginástica. O depoimento dela assumindo que tem TDAH e que toma medicação para tratar o transtorno, junto a foto com uma medalha de ouro, associa o tratamento ao sucesso. Esta imagem (figura 4) pode transmitir a ideia de que as pessoas diagnosticadas com TDAH e que tomam medicamentos podem obter sucesso em suas atividades, uma estratégia de marketing.

É interessante destacar que o metilfenidato é um dos estimulantes que consta na "Lista proibida 2016 - Código de Antidopagem" como uma substância proibida. Entretanto, há um documento com informações médicas do Programa Mundial de Antidopagem (World Anti-Doping Agency/International Olympic Committee - WADA- 
AMA/IOC), onde consta que não há necessidade de interromper o tratamento durante os períodos de competição, pois poderá causar efeitos negativos, incluindo efeitos adversos no controle dos sintomas. É importante ressaltar que, se informado o uso para tratamento médico e autorizado pelas autoridades esportivas, não será considerado doping. $\mathrm{O}$ argumento para constar nesta lista de tratamento médico é pela possibilidade de os atletas apresentarem comportamentos de risco e se envolverem em situações de conflito.

Vale ressaltar que o doping é considerado quando há o uso de substâncias ou métodos capazes de aumentar artificialmente o desempenho físico, seja prejudicial à saúde do atleta, além de ser contrário aos valores do esporte.

$\mathrm{Na}$ bula da Ritalina consta que a Ritalina ${ }^{\circledR}$ LA pode dar resultado falso positivo em testes para o uso de drogas. Isto inclui testes utilizados no esporte, podendo causar doping. O metilfenidato é um estimulante do sistema nervoso central que é indicado para aumentar a concentração, fator bastante exigido a uma ginasta olímpica. Os efeitos do metilfenidato podem causar um desempenho de atividades melhor às pessoas que fazem uso deste medicamento em relação às demais.

Mediante estes fatos, como podemos ensinar crianças e adolescentes a adentrar neste mundo competitivo honestamente, uma vez que seus "concorrentes" estão autorizados a fazer uso de drogas que promovem um alto rendimento? Além disso, este "sucesso" é divulgado pela mídia como propaganda do TDAH, o que propicia cada vez mais que a lógica medicalizante torne-se usual na contemporaneidade.

\section{Considerações finais}

As estratégias do risco que induzem as pessoas a aderirem ao tratamento medicamentoso, somadas ao DSM, que legitima o diagnóstico de transtornos mentais, fazem com que questões de cunho social, educacional, familiar, político passem a pertencer exclusivamente ao campo médico. Isso parece ocorrer devido à identificação 
da indústria farmacêutica de um nicho de mercado rentável.

Pôde-se constatar a existência de um significativo investimento em marketing por parte da indústria farmacêutica, promovendo o aumento das vendas de medicamentos (Angell, 2007; Conrad; Schneider, 1992; Bianchi et al, 2016; Whitaker, 2011, Frances, 2016). Nesta direção, o campo virtual caracteriza-se como um meio apropriado para o amplo alcance da população. As informações sobre o TDAH são divulgadas nas redes sociais didaticamente, de modo que as teorias científicas complexas fiquem bastante claras, literalmente desenhadas para o bom entendimento do público alvo (famílias e profissionais da educação e saúde). Desta forma, a "transmissão" do TDAH ocorre pelos milhões de compartilhamentos nas redes sociais de informações sobre o transtorno.

A ABDA aparece com a roupagem de benfeitora, mas está suscetível a manipulações e condução de processos medicalizantes que são de interesses dos próprios mantenedores da entidade. Os materiais disseminados pela ABDA são um modo de explanar claramente e simplificar os conteúdos do DSM, cujo objetivo é atingir a população com estas informações ditas de cunho científico. A identificação das pessoas com as cenas descritas nas imagens divulgadas pela ABDA mostra como os problemas cotidianos são facilmente transformados em patológicos, e assim, as pessoas são induzidas a procurar um médico especialista, recebendo então o diagnóstico de TDAH e a prescrição do medicamento.

O TDAH mascara muitos problemas, talvez por isso é tão bem aceito na sociedade, e a Ritalina aparece como um produto de excelência. Nesse sentido, o marketing tem como função satisfazer as necessidades e desejos das pessoas. Deste modo, o investimento nessa área é inevitável para estabelecer o fluxo desde o fabricante até o consumidor. A ABDA parece desempenhar um papel fundamental, como o cerne deste sistema que vai desde os fabricantes dos medicamentos, as associações de profissionais, entre outros interessados, até os consumidores do produto. 
É evidente que não é possível decifrar todos os aspectos que nos levaram a chegar no século XXI com uma verdadeira epidemia de transtornos mentais. Porém, algumas transformações, como a tecnológica, nos indicam como é possível atingir grande parte da população com uma patologia causada por um "vírus" que foi midiaticamente criado.

\section{Referências}

ABDA - Associação Brasileira de déficit de atenção. (2016). Associação Brasileira de $\begin{array}{llll}\text { déficit de atenção (Facebook). Recuperado de } & \end{array}$ https://www.facebook.com/ABDATDAH/

Angell, M. (2007). A verdade sobre os laboratórios farmacêuticos. Rio de Janeiro: Editora Record.

Augusto, A. (2015). Governando crianças e jovens: escola, drogas e violência. In H. Resende (Org) Michel Foucault: o governo da infância. Belo Horizonte: Autêntica.

Bianchi, E. et al. (2016). Medicalización más allá de los médicos: marketing farmacéutico en torno al Trastorno por Déficit de Atención e Hiperactividad en Argentina y Brasil (1998-2014). Saúde Soc. São Paulo, 25(2), p.452-462. doi: http://dx.doi.org/10.1590/S0104-12902016153981.

Breggin, P. R. (2001). Talking back to Ritalin: what doctors aren't telling you about stimulants for children. Cambridge: Da Capo Press.

Caponi, S. (2012). Classificar e Medicar: a gestão biopolítica dos sofrimentos psíquicos. Interthesis, 9(2). doi: http://dx.doi.org/10.5007/18071384.2012v9n2p101

Caponi, S. (2014). O DSM-V como dispositivo de segurança. Physis 24(3), 741-763. doi: http://dx.doi.org/10.1590/S0103-73312014000300005 
Carvalho, A. F. (2015) Por uma ontologia política da (d)eficiência no governo da infância. In H. Resende (Org). Michel Foucault: o governo da infância (pp. 2547). Belo Horizonte: Autêntica.

Collares, C. A. L. e Moysés, M. A. (2014). A Educação na era dos transtornos. In L. S. Viégas et al. (Org). Medicalização da educação e da sociedade: ciência ou mito? Salvador: EDUFBA.

Conrad, P. (2007). The medicalization of society: on the transformation of human conditions into treatable disorders. Baltimore: The Johns Hopkins University Press.

Conrad, P. e Bergey, M. (2014). The impending globalization of ADHD: Notes on the expansion and growth of a medicalized disorder (vol. 122). (s.I.): Social Science and Medicine.

Conrad, P., \& Schneider, J. W. (1992). Deviance and medicalization: from badness to sickness. Philapelphia: Temple University Press.

Dunker, C. I. L. (2014). Questões entre a psicanálise e o DSM. J. Psicanal, 47(87), 79107.

Foucault, M. (1994). Dits et écrits III. París: Gallimard.

Foucault, M. (2008). Segurança, Território, População. São Paulo: Martins Fontes.

Foucault, M. (2013). História da sexualidade I: $A$ vontade de saber. (23 ${ }^{\mathrm{a}}$ ed.) Rio de Janeiro: Graal.

Frances, A. (2015). Fundamentos do diagnóstico psiquiátrico: respondendo as mudanças dos DSM-5. Porto Alegre: Artmed.

Frances, A. (2016). Voltando ao Normal (Trad. Heitor M. Corrêa). Rio de Janeiro: Versal.

Hacking, I. (2000). Múltipla personalidade e as ciências da memória. Rio de Janeiro: José Olympio. 
Mitjavila, M. (2002). O risco como recurso para a arbitragem social. Tempo soc, 12(2), 129-145.

Silveira, D. S. (2015). Governamentalidades, saberes e políticas públicas na área de Direitos Humanos da criança e do adolescente. In: Resende, H. (Org). Michel Foucault: o governo da infância (pp. 57-83). Belo Horizonte: Autêntica.

Smith, M. (2012). Hyperactive: The Controversial History of ADHD. London: Reaktion Books.

Veiga-Neto, A. (2009). Teoria e método em Michel Foucault (im)possibilidades. Cadernos de Educação, (34), 83-94. doi: http://dx.doi.org/10.15210/caduc.v0i34.1635.

Whitaker, R. (2016). Transformando crianças em pacientes psiquiátricos: fazendo mais mal do que bem. In: Caponi, S.; Vásquez, M. F.; Verdi, M. (Org). Vigiar e medicar: estratégias de medicalização da infância (pp. 13-28). LiberArs: São Paulo.

Whitaker, R. (2011). Anatomía de una epidemia: medicamentos psiquiátricos y el asombroso aumento de las enfermedades mentales (Trad. J. Manuel Álvarez). Madrid: Capitán Swing.

\section{Formato de citación}

Martinhago, F. (2018). TDAH nas redes sociais: caminhos para a medicalização da infância. Psicología, Conocimiento y Sociedad, 8(2), 95-117. doi:

http://dx.doi.org/10.26864/PCS.v8.n2.6 